\title{
Technological Benchmarking : A Case Study in Product Development by a Small Manufacturer
}

\author{
W. P. Lewis and A. E. Samuel \\ Department of Manufacturing Engineering, University of Melbourne, \\ Grattan Street, Melbourne, Australia, 3052
}

Benchmarking originated in large organizations with considerable resources for conducting internal reviews and special investigations. This paper is concerned with benchmarking by a small manufacturer endeavouring to survive and prosper in a global economy. The company has embarked on an exercise to benchmark its core technological activities. The results are reported as a case study to demonstrate the development of methods appropriate to small scale, discrete product manufacturing.

\section{INTRODUCTION}

This paper examines the development of benchmarking procedures for the important core technological activities of a small manufacturer engaged in batch production of discrete products for niche markets in Pacific rim and other countries. The focus is on small firms since in many industrial economies they form the backbone of manufacturing industry and their role has often been under-valued [1]. Benchmarking is conceived here as " the search for industry best practices that lead to superior performance " [2], and a case study is presented of the approach adopted by one such firm.

The Company concerned employs 100 people with an annual turnover of $\$ 50 \mathrm{~m}$ (Australian currency). It is engaged in the batch production of motor and engine driven centrifugal pumps and related water handling and filtration equipment, sales of around 100,000 units per year, $75 \%$ for the domestic market, $25 \%$ exported. The company has manufacturing facilities for material removal, cold forming by pressing and deep drawing, diecasting, welding, manual and automated assembly, product and component testing; there is close liaison with plastic injection moulders. During 1993 the Company's management decided that benchmarking was an essential tool to ensure that their firm's core activities were in accordance with world best practice. Expert advice was received that the planning and execution of a traditional benchmarking study would require well over 1,000 hours of staff time [3] and thus be a relatively expensive operation, so the Company planned a five-stage strategy in which there would be a progressive commitment of resources as each stage was successfully completed. 
The actions to be taken in the Company's five-stage strategy are set out below in the context of discrete product manufacturing considered as a business process in which there are inputs of energy, information and raw materials which are transformed into outputs of marketable products by the application of human and physical resources in an effective and efficient manner.

(1) Compare costs of manufacturing inputs to those obtaining in industrialised nations in Europe and around the Pacific rim. If input costs found to be competitive proceed to stage (2), if not reassess future of company.

(2) Identify performance drivers which are crucial determinants of long term company success, and the sub-processes with which they are associated.

(3) Analyse the performance drivers, dealing separately with those which are amenable to objective evaluation and those which require benchmarking.

(4) Select a typical product for a pilot study and evaluate the performance driver(s) carried forward from (3) for this product. Review the results of the evaluation, and proceed if the predicted benefits outweigh the expected costs.

(5) Conduct a full scale benchmarking study of the performance driver(s) carried forward from stage (3).

This strategy has been applied in the investigation described below.

\section{INVESTIGATION}

\subsection{Stage 1 - Manufacturing Inputs}

The Company's manufacturing manager toured the world and collected data from Germany, Italy, U.K., U.S.A., Korea, Japan, Taiwan on local costs of (a) steel, aluminium, copper, (b) purchased items such as capacitors, seals, bearings, (c) skilled labour, (d) electrical power. His conclusion : all input costs for the Company were lower than those in Europe, U.S.A. and Japan; some costs were higher than in Korea, Taiwan, but overall costs in those countries were similar to those in Australia.

\subsection{Stage 2 - Performance Drivers}

A means/ends analysis of the operations of a manufacturing organization yields a hierarchy of goals and goal statements in which the statement at any level of the hierarchy constitutes the means for achieving the ends represented by the statement in the level immediately above it, as indicated in Fig. 1. The top level corresponds to the ultimate goals of the Company, namely profitability and growth. The hierarchy in Fig. 1 proceeds down to the level of new product development and shows the relationship of this activity to higher goals. What are the "performance drivers " [4] for the Company - the factors which have a crucial influence, direct or indirect, on its successful operation and future prosperity? The company's management identified the following factors, both related to new product development.

(a) Product Range - a range of models sufficiently all-embracing to reflect the markets' requirements for performances covering a wide range of fluid flows in different applications.

(b) Short Lead Time for new product development to enable fast, flexible responses to changing conditions.

This information was carried forward to the next stage of the investigation. 


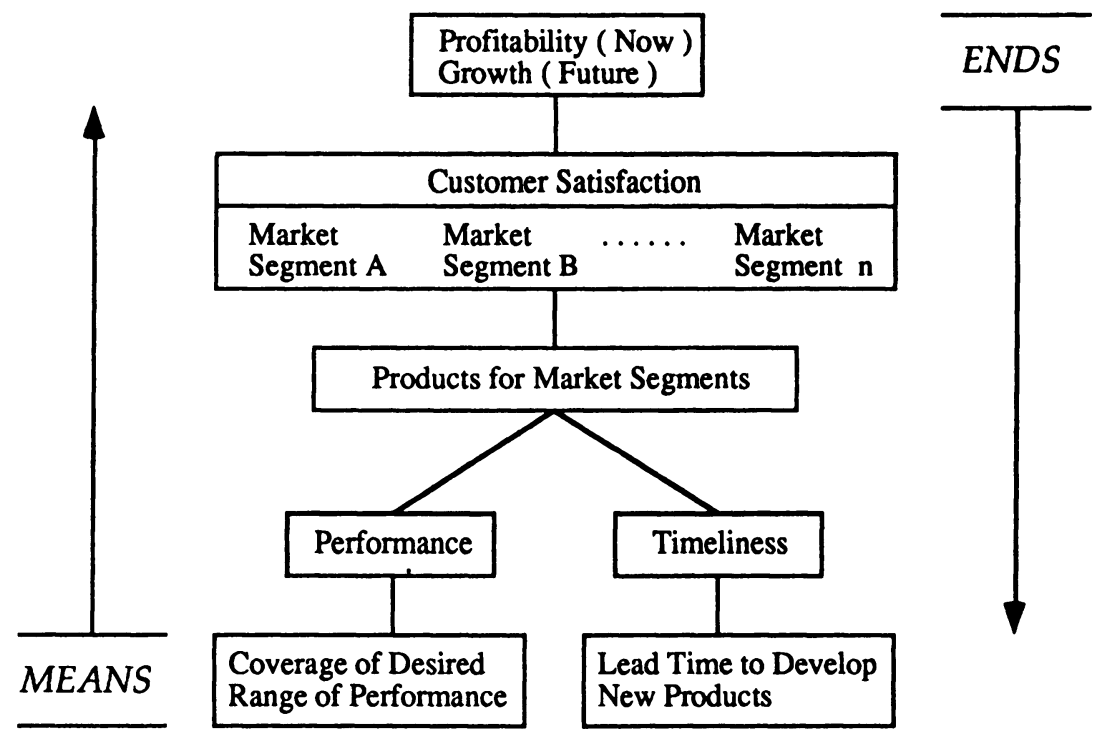

Fig. 1. Means / Ends Analysis : Relation of New Product Development to Company Goals.

\subsection{Stage 3 - Analysis}

Product Range. The performance characteristics of the Company's products are continuous variables such as pump flow rates and efficiencies, motor powers, fluid storage capacities and so on. Products are discrete items and each model in a particular range will provide optimum performance for one discrete duty and less than optimum performance for other duties. The problem is then one of matching the number of models in a product range covering a spectrum of performances to the manufacturing resources available, when there is a discrete number of models and a continuously variable performance characteristic. For centrifugal pumps this problem has been investigated and effectively solved [4], and the methods developed can be extended to other products manufactured by the Company where the product range is also amenable to objective evaluation.

The picture changes if we move to a higher level of the hierarchy, say to "customer satisfaction". This is not a holistic concept because of the segmented nature of the market being served. One segment which has become prominent in recent years is concerned with solar energy applications, e.g. for heating swimming pools ( with the $100 \%$ vision of hindsight this might well have been expected ). The demand here is for low capacity pumps to circulate water through solar booster coils where there is a large pressure drop and a need for higher pressure pumps. 
However, the Company was slow to recognize this demand and lost a significant market share as a result. It has now benchmarked its market research in terms of capacity to identify markets for products associated with or employing new or emerging technologies. Measures of performance on this criterion were obtained from comparisons with a strong local competitor and a large and well-established international manufacturer, using an ordinal scale with ratings of "high", "medium" and "low". As a result of this benchmarking exercise weaknesses in market research procedures were exposed and action initiated to remedy them.

Short Lead Times for New Product Development. The quest for short lead times in product development led the Company to consider benchmarking its product development processes. This presented problems some of which have been solved while the Company and the authors are still grappling with others. For example, the rate at which competitors introduced new products to the market was known, but their development times were not, although reasonable guesses could be made. In the event the company decided to embark on a self-assessment of its product development processes in depth and began to monitor this aspect of its operations by recording avoidable delays and calculating a performance index $\left(\mathrm{P}_{i}\right)$ for each product development programme as

$\mathrm{Pi}=\frac{\text { (Time to develop product) }- \text { ( Time lost due to avoidable delays ) }}{\text { (Time to develop product ) }} \times 100$.

\subsection{Stage 4 - Pilot Study}

The Company's management and the authors then agreed to select a typical product for investigation whose development could be studied as part of an ongoing research programme into benchmarking manufacturing systems. The 6 litre tank assembly chosen is part of a domestic pressure system, a recent product added to an existing range by the manufacturer who already makes and sells systems having water storage capacities of 10, 15, 20 and 30 litres. It was developed in response to a competitor known to be about to market a similar product.

The design concept was obtained by scaling down from the 10 litre system, although it was realised that the sizes and shapes of some, possibly all, components must change if only because water and air pressures do not change. Fig. 2 shows a typical arrangement of components in a product of this type. An expandable diaphragm of nitrile rubber receives water under pressure from a small centrifugal pump and discharges it through a nozzle to provide pressurized water to a domestic system in a house or building without access to conventional water supply in a town or city. The diaphragm is mounted in an enclosing tank and kept in place by a keeper ring. The air in the tank surrounding the diaphragm is compressed both to cushion the expansion of the diaphragm and to assist the rapid egress of water from it. Other details of construction and operation can be inferred from Fig. 2. 


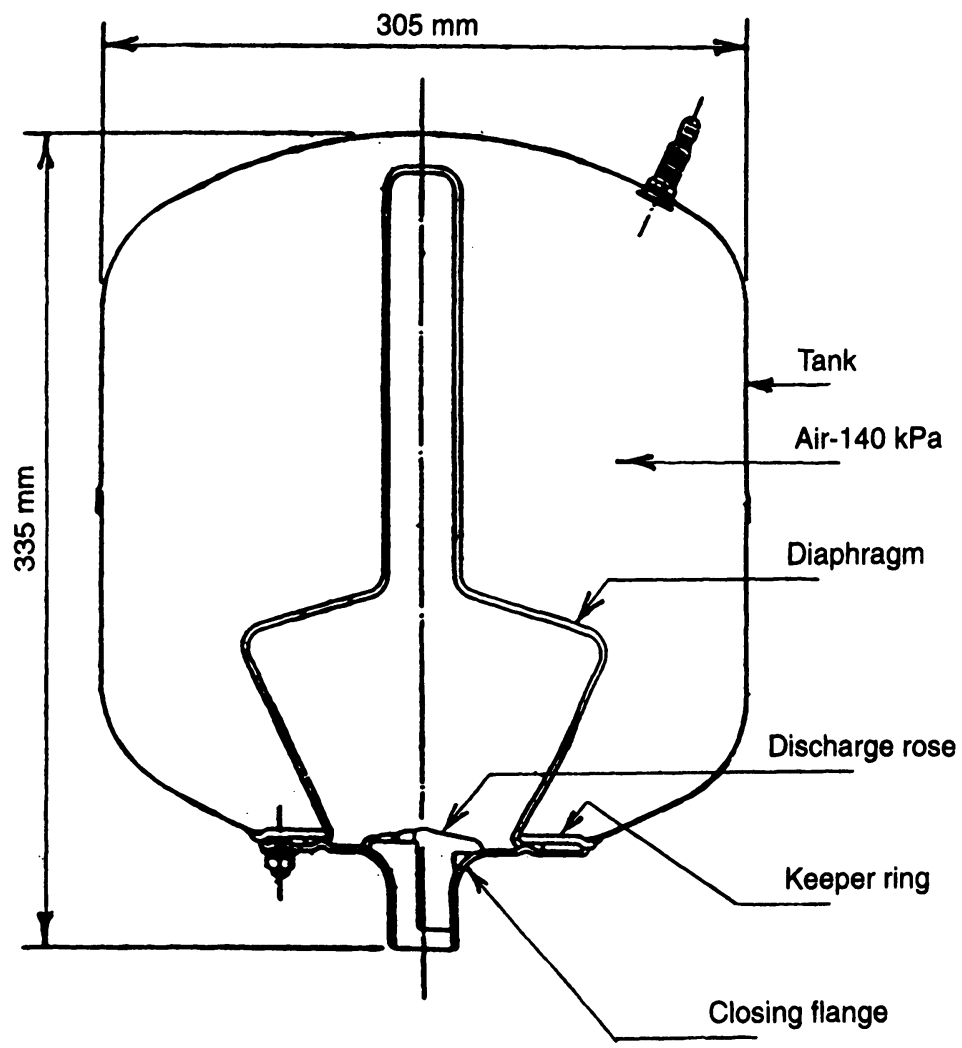

Fig. 2. Sectional Arrangement of 6 Litre Tank Assembly.

Delays were experienced in the development of the 6 litre tank assembly in that it took longer than expected to create a new geometry of diaphragm to suit this application and to seek out and liaise with specialist suppliers of steel pressings to ensure that the cost of the tank was in line with the programme budget. There were also unforeseen manufacturing problems associated with the welding of the keeper ring to the outer casing and with forming the curved profile of the discharge nozzle. As a result of these delays the performance index $P_{i}$ was $63 \%$, a sufficiently low value to cause the company concern. As a result of this benchmarking exercise the Company has instituted a database for each product development programme comprising :

- short description of product

- graphical depiction of decision making via relevant DIN (see next page)

- checklist for deployment of design resources (see next page)

- performance index $\mathrm{P}_{\mathrm{i}}$, and if $\mathrm{P}_{\mathrm{i}}<100 \%$ the reasons for this. 
In addition the Company has initiated research into information flows, decision making, and design resource allocation during product development. The results from the pilot study are summarized in the Appendices. Table A1 in Appendix 1 shows the Design Decision Table (DDT) for the 6 litre tank assembly, while Appendices 2 and 3 show the Design Information Network (DIN) and Design Resources Matrix (DRM) respectively.

In Table A1 the key design decisions taken during development of the product are listed in the left hand column and are identified by a two-letter code, e.g. DV for the decision on the magnitude of the diaphragm volume. The information input to this decision was the customer need (denoted $\mathrm{CN}$ in column 3 ) as defined by a crossfunctional team working on quality function deployment (QFD) as noted in column 2. The outcome of this decision is shown in column 4 as the numerical value 6 litres. Similar explanations apply to the other entries in the Table. In the formulation of the project two other key design management decisions were taken re performance targets, namely (i) the diaphragm life was to be not less than 250,000 cycles of operation, a figure based on use of existing products by domestic comsumers, and (ii) the manufacturing cost (TC in Appendix 2) was not to exceed a value set by the selling prices of competitors. Other notation in Table A1 consists of EP, knowledge of existing products, and $\Delta \mathrm{p}$, pressure loss through the discharge nozzle.

DIN's make visible and display the path through the array of key decisions by which a final outcome is reached, and exhibit this path to demonstrate the process of decision making in an objective manner. Traceability of and accountability for decisions are important themes in the ISO 9000 series of quality standards. In ISO 9001, for example, there are clauses dealing with "Verification that design outputs meet design input requirements", and with "Responsibility for initiation of action to prevent the occurrence of product nonconformity" - clearly requiring traceability of design decisions. In this case the Company's management considered benchmarking of product quality to be a matter for future investigation when the DIN in Appendix 2 would be an important analytical tool.

The Design Resources Matrix in Appendix 3 is an example of a tool adapted from Eppinger's work [6] by the authors to assist the Company commit resources to the key design decisions for which they are to be deployed. (In graph theoretic terms [7] a DIN is a directed graph and the DRM is the corresponding adjacency matrix.) "Resources" here is to be interpreted broadly to include intellectual design skills such as creativity and judgement as well as marketing knowledge about customer needs and manufacturing knowledge of the capacities of specialist suppliers. A study of the availability and timeliness of these resources and the use made of them in practice is under way at the time of writing this paper. Preliminary results suggest that the Company's current procedures are far from perfect and that designers are prepared to make guesses in order to meet tight deadlines.

The pro's and con's of proceeding to stage (5) are currently being weighed up by Company's management. The results from the first four stages of the benchmarking 
exercise have yielded valuable data on the strengths and weaknesses of existing operations and the Company's capacity for future growth and profitability.

\section{CONCLUDING COMMENTS}

Benchmarking has been considered from the point of view of a small manufacturer which is internationally competitive and intends to remain so. Small manufacturers are the backbone of many industrial economies, but the need for them to benchmark their practices has been insufficiently acknowledged, hence this paper.

All industrial companies but particularly those with a limited capital base have to marshal resources carefully to ensure profitable operation now and long term growth in the future. Benchmarking procedures for small manufacturers should therefore proceed in carefully designed stages, so that the value of the results obtained is proportionate to the effort expended in each stage e.g. via a series of hurdles and a pilot study as in this case study.

During the investigation reported here benchmarking was carried out in accordance with a carefully devised strategic plan, working through various levels in the means/ends hierarchy using subjective and objective rating scales as appropriate and relying on both internal and external performance data as bases for the comparisons made. On each occasion the Company gained new insights into the effectiveness and efficiency of its operations, thus demonstrating the flexible and wide-ranging nature of the benchmarking process. It is hoped that the paper will provide a useful guide to benchmarking proce-dures suited to the needs of small manufacturers and suitable for adoption by them.

\section{REFERENCES}

1. McKinsey and Company, Emerging Exporters : High Value-Added Manufacturing Exporters, Australian Manufacturing Council, Melbourne, 1993.

2. R.C. Camp, Benchmarking: The Search for Industry Best Practices, Quality Press, Milwaukee, 1989.

3. National Industry Extension Service, Benchmarking Self-Help Manual, Australian Government Publishing Service, Canberra, 1993.

4. C.J. McNair, Benchmarking : A Tool for Continuous Improvement, Harper Business, New York, 1992.

5. P. McAree, Planning an Range of Centrifugal Pumps, Proc. I. Mech. E., 186 (1972) 595-602.

6. S.D. Eppinger and K.R. McCord, Managing the Integration Problem in Concurrent Engineering, Working Paper No. 95, International Center for Research on the Management of Technology, Massachusetts Institute of Technology (1993).

7. N. Biggs, Algebraic Graph Theory, Cambridge University Press, 1974. 


\section{APPENDIX 1}

TABLE A1. Design Tasks and Key Decisions.

\begin{tabular}{|c|c|c|c|c|}
\hline \multicolumn{2}{|l|}{$\begin{array}{l}\text { Nature of Decision } \\
\text { - denoted (xx) }\end{array}$} & $\begin{array}{l}\text { Decision } \\
\text { Making Procedure }\end{array}$ & $\begin{array}{l}\text { Information } \\
\text { Input to Decision }\end{array}$ & $\begin{array}{l}\text { Quantitative } \\
\text { Result }\end{array}$ \\
\hline \multicolumn{5}{|l|}{ Diaphragm } \\
\hline Diaphragm volume & (DV) & QFD team & \multicolumn{2}{|c|}{ Customer need (CN) 6 litres } \\
\hline \multicolumn{3}{|c|}{ Replaceable diaphragm (DR) QFD team } & \multirow{2}{*}{$\begin{array}{l}\text { Customer need (CN) } \\
\text { DV, TS, KD }\end{array}$} & \multirow{2}{*}{$\begin{array}{l}\text { Adjustment } \\
\text { to layout } \\
\text { Special 3D shape }\end{array}$} \\
\hline Diaphragm shape & (DS) & Personal creativity & & \\
\hline Water pressure & (DP) & QFD team & $\mathrm{CN}, \mathrm{EP}$ & $\sim 350 \mathrm{kPa}$ \\
\hline \multicolumn{5}{|l|}{ Tank } \\
\hline Tank air pressure & (TP) & QFD team & $\mathrm{CN}, \mathrm{EP}$ & $\sim 200 \mathrm{kPa}$ \\
\hline Tank volume & (TV) & \multirow{2}{*}{$\begin{array}{l}\text { Simulation - } \\
\text { Prediction by calc'n } \\
\text { Judgement }\end{array}$} & DV, DP, TP & 18 litres \\
\hline Tank shape - L/D & (TS) & & $\mathrm{CN}, \mathrm{EP}, \mathrm{TV}$ & $\mathrm{L} / \mathrm{D} \sim 0.75$ \\
\hline Tank material & (TM) & \multirow{2}{*}{$\begin{array}{l}\text { Judgement } \\
\text { (Informal analysis o } \\
\text { AS } 2971\end{array}$} & \multirow{2}{*}{$\begin{array}{l}\text { EP } \\
\text { f cost-effectiveness of } \\
\text { TS, TP, TM }\end{array}$} & $\begin{array}{l}\text { Mild steel } \\
\text { f alternatives ) }\end{array}$ \\
\hline Wall thickness & $(T W)$ & & & $1 \mathrm{~mm}$ \\
\hline $\begin{array}{l}\text { Internal surface } \\
\text { Tank Outlet }\end{array}$ & (TI) & Design logic & DR, TM & $\begin{array}{l}0.1 \mathrm{~mm} \text { thickness; } \\
\text { anti-corrosion paint }\end{array}$ \\
\hline \multicolumn{2}{|c|}{ Keeper ring diameter (KD) } & \multirow{3}{*}{$\begin{array}{l}\text { Adjustments to } \\
\text { suit DS } \\
\text { Experimental trial } \\
\text { and error to ensure } \\
\text { manufacturability } \\
\quad \text { do. }\end{array}$} & \multirow{2}{*}{$\begin{array}{l}\text { DR, DS, TS } \\
\text { TW, KD }\end{array}$} & $12 \mathrm{~mm}$ \\
\hline Ring thickness & $(\mathrm{KT})$ & & & $3 \mathrm{~mm}$ \\
\hline Discharge nozzle p & $\begin{array}{l}\text { file } \\
\text { (NP) }\end{array}$ & & $\mathrm{CN},(\Delta \mathrm{p}), \mathrm{KD}$ & $\begin{array}{l}\text { radius of curva- } \\
\text { ture of profile }\end{array}$ \\
\hline
\end{tabular}


APPENDIX 2 - Design Information Network

$$
\text { 흔 ㅎํㄴ }
$$

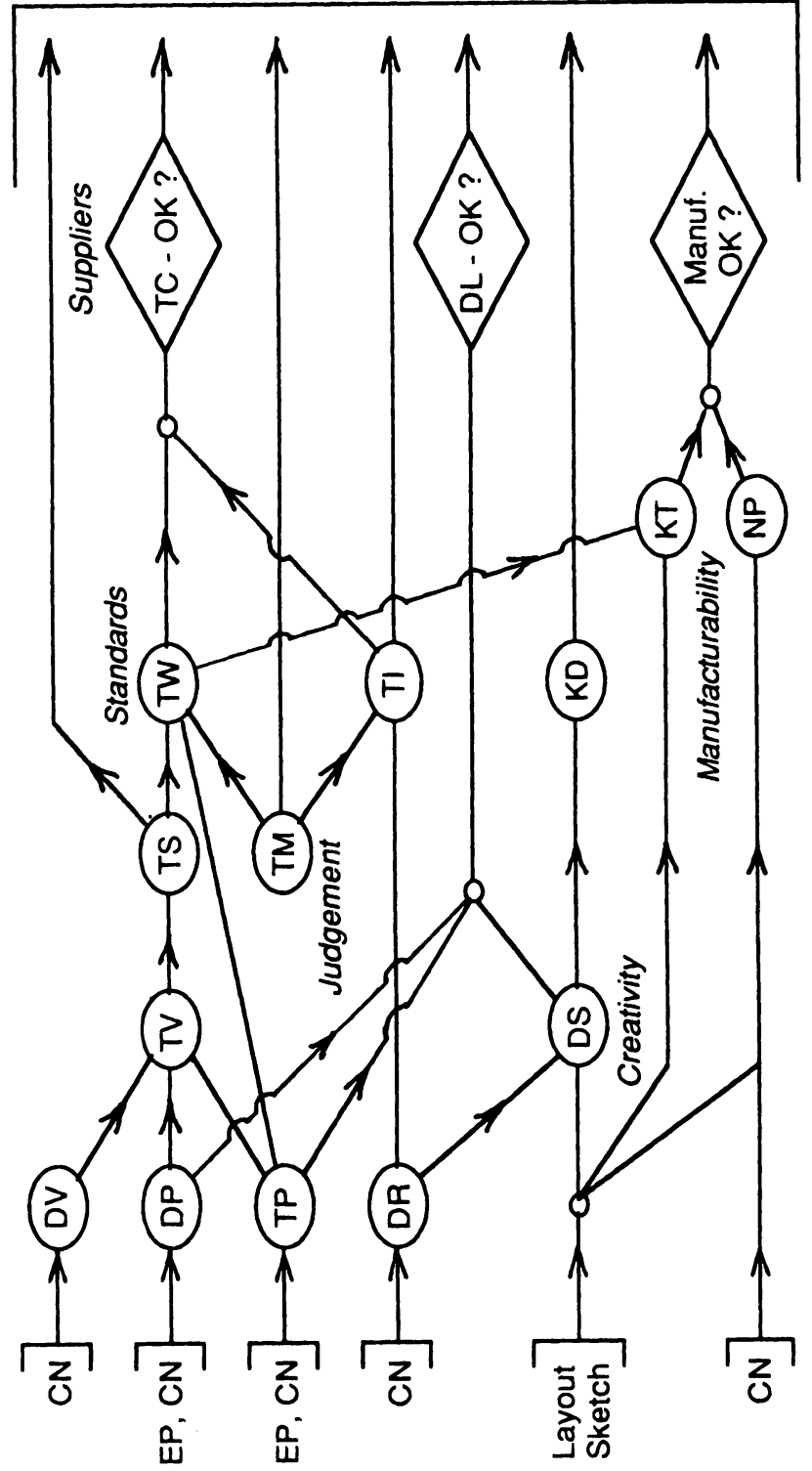


APPENDIX 3 - Design Resources Matrix

\begin{tabular}{|c|c|c|c|c|c|c|c|c|c|c|c|}
\hline & & 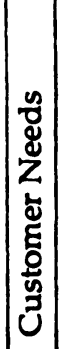 & 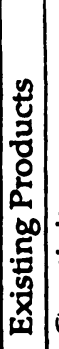 & 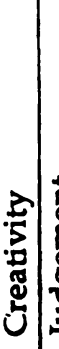 & 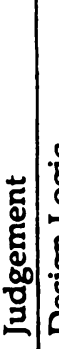 & 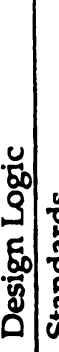 & סे & : & 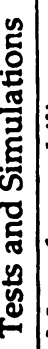 & 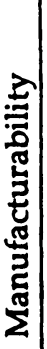 & 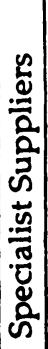 \\
\hline Diaphragm Volume & DV & $\checkmark$ & & & & & & & & & \\
\hline Diaphragm Air Pressure I & DP & $\checkmark$ & $\checkmark$ & & & & & & & & \\
\hline Replaceable Diaphragm I & DR & $\checkmark$ & & & & & & & & & \\
\hline Diaphragm Shape & DS & & & $\checkmark$ & & & & & & & \\
\hline Water Pressure in Tank & TP & $\checkmark$ & $\checkmark$ & & & & & & & & \\
\hline Tank Volume & TV & $\checkmark$ & & & & & & & & & \\
\hline Tank Shape & TS & & $\checkmark$ & & $\checkmark$ & & & & & & \\
\hline Tank Material & TM & & $\checkmark$ & & $\checkmark$ & & & & & & \\
\hline Tank Wall Thickness & TW & & & & & & $\checkmark v$ & $\checkmark$ & & & \\
\hline Internal Surface of Tank & $\mathrm{TI}$ & & & & & $\checkmark$ & & $\checkmark$ & & & \\
\hline Keeper Ring Diameter & KD & & & & & $\checkmark$ & & & & & \\
\hline Keeper Ring Thickness & KT & & & & & & & & & $\checkmark$ & \\
\hline Discharge Nozzle Profile & $\mathrm{NP}$ & $\checkmark$ & & & & & & & & $\checkmark$ & \\
\hline Diaphragm Life & $\mathrm{DL}$ & $\checkmark$ & & & & & & $\checkmark v$ & $\checkmark$ & & \\
\hline Cost of Tank Assembly & TC & $\checkmark$ & & & & & & & & & $\checkmark$ \\
\hline
\end{tabular}

A tick in a cell of the matrix identifies a Design Resource (column) which has to be allocated to the process of making a key Design Decision ( row ). 